\title{
Effect of tramadol addiction alone and its co-abuse with cannabis on urinary excretion of Copper, Zinc, and Calcium among Egyptian addicts
}

\author{
Ibrahim El-Safty ${ }^{1}$, Elsayed Eltamany ${ }^{2}$, Ahmed Shouman $^{3}$, Omayma El-Gamel ${ }^{4}$, Ahmed Nada $^{5}$, Wesam Ali ${ }^{6}$
}

1. Chemistry Department, Faculty of Education, Ain-Shams University, Heliopolis, Roxy, Cairo, Egypt.

2. Chemistry Department, Faculty of Science, Suez Canal University, Ismailia, Egypt.

3. Department of Community, Environmental and Occupational Medicine, Faculty of Medicine, Ain-Shams University, Cairo, Egypt.

4. Clinical Pathology Department, El-Demerdash Hospital, Faculty of Medicine, Ain-Shams University, Cairo, Egypt. 5. Atomic Energy Authority, Nasr City, Cairo, Egypt.

6. Chemistry Department, Faculty of Science, Suez Canal University, Ismailia, Egypt.

\section{Emails:}

Ibrahim El-Safty: elsafty54@yahoo.com, Elsayed Eltamany: s.eltamany51@yahoo.com, Ahmed Shouman: Shouman1@yahoo.com, Omayma El-Gamel: oelgamel92@hotmail.com, Ahmed Nada: ashnada59@hotmail.com, Wesam Ali:wesamahmed800@gmail.com.

\begin{abstract}
Background: The use of illicit drugs has become a worldwide health problem. Substances with the potential to be abused may have direct or indirect effects on physiologic mechanisms that lead to organ system dysfunction and diseases.

Objective: The present study aims to investigate the structural and reabsorption integrity of the nephron among Egyptian addicts of tramadol alone and coabused with cannabis.

Methods: Sixty-five males were included in the study, they were classified into control group (G1=19), tramadol addicts group (G2=18), and tramadol coabused with cannabis addicts group (G3=28). Parameters investigated for structural integrity were urinary levels ofleucineaminopeptidase and $\mathrm{N}$-acetyl- $\beta$-D-glucosaminidase, and urinary parameters for reabsorption integrity were levels of copper and zinc as well as calcium, also urinary creatinine was measured. In addition, urinary levels of tramadol and tetrahydrocannabinol were estimated.
\end{abstract}

Results: Among the two addicted groups, all measured parameters were not significantly different in comparison with the control group except for urinary calcium excretion which was found to be significantly increased among the two addicted groups.

Conclusion: Both tramadol addiction alone or coabused with cannabis causes increased urinary excretion of calcium, indicating reabsorption dysfunction of calcium without affecting structural integrity along the nephron.

Keywords: Enzymuria, copper, zinc, calcium, reabsorption impairment, tubular structural integrity.

DOI: https://dx.doi.org/10.4314/ahs.v18i3.35

Cite as: El-Safty I, Eltamany E, Shouman A, El-Gamel O, Nada A, Ali W. Effect of tramadol addiction alone and its co-abuse with cannabis on urinary excretion of Copper, Zinc, and Calcium among Egyptian addicts. Afri Health Sci. 2018;18(3): 767-775. bttps://dx.doi. org/10.4314/abs.v18i3.35
Corresponding author:
Ibrahim El-Safty,
Chemistry Department,
Faculty of Education,
Ain-Shams University, Heliopolis,
Roxy, Cairo, Egypt.
Tel: +201065567240 / +201284111655
E-mail: elsafty54@yahoo.com

\section{Introduction}

The use of illicit drugs has become a worldwide health problem. It leads to numerous consequences at the health, economic, social and legal levels. These consequences interfere with the development of the countries and their efforts to respond to the needs of their populations. Apart from its economic cost, drug abuse leads to social problems among family members, abnormal behavior, crime, health and psychological problems as well as economic difficulties ${ }^{1}$.

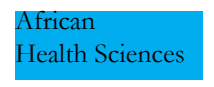

C 2018 El-Safty et al. Licensee African Health Sciences. This is an Open Access article distributed under the terms of the Creative commons Attribution License (https://creativecommons.org/licenses/BY/4.0), which permits unrestricted use, distribution, and reproduction in any medium, provided the original work is properly cited. 
Tramadol (Tr) is a synthetic opioid from the aminocyclohexanol group and is commonly used in clinical practice as analgesic for treatment of moderate to severe pain ${ }^{2}$. Tramadol is free of side effects of traditional opioid such as the risk for respiratory depression ${ }^{3}$ and drug dependence $^{4}$. So, the abuse potential of tramadol is considered low or absent ${ }^{5}$, which is in contrast to other opioids.

Cannabis was used a long time ago for both recreational and medicinal purposes. The plant Cannabis sativa (Indian hemp) is the source of different psychoactive products. Marijuana comes from leaves, stems, and dried flower buds of the plant. Hashish is a resin obtained from flowering buds of the hemp plant ${ }^{6} . \Delta$ 9-tetrahydrocannabinol $(\Delta 9$-THC) is the primary psychoactive compound and contributes to the behavioral toxicity ofcannabis ${ }^{7}$.

Calcium $(\mathrm{Ca})$ is the most abundant divalent ion $(\mathrm{Ca} 2+)$ in the body ${ }^{8}$. Calcium is reabsorbed along all segments of the nephron. The proximal tubule is the primary tubular segment where most of the filtered calcium is reabsorbed. Under normal condition, 98-99\% of the calcium which passes into the tubule is reabsorbed. Approximately 60$70 \%$ of the filtered calcium is reabsorbed in the proximal convoluted tubule, $20 \%$ in the loop of Henle, $10 \%$ by the distal convoluted tubule, and $5 \%$ by the collecting duct ${ }^{9}$. Any calcium that is not reabsorbed then passes into what is now urine and into the bladder.

Copper $(\mathrm{Cu})$ is important for all functions of many cellular enzymes ${ }^{10}$. The copper transporters ATP7A and ATP7B are expressed at distinct regions of the kidney ${ }^{11}$. They are both expressed in the glomeruli in minor amounts. ATP7A is localized in the proximal and distal tubules, while ATP7B is expressed in the loop of Henle. The two copper transporters work together to maintain copper balance within this tissue. The ability of ATP7A to traffic to basolateral membrane (an event associated with copper export) in response to copper elevation strongly suggests that ATP7A plays the major role in exporting copper from renal cells for reabsorption into the blood and in protecting renal cells against copper overload ${ }^{12}$. In another research, ATP7B expression in the loops of Henle suggests that once in the filtrate, ATP7B is responsible for copper reabsorption ${ }^{11}$. Previous data suggest that copper may be reabsorbed by the same pathway as that involved in iron reabsorption ${ }^{13}$, which occurs between the proximal and distal convoluted tubules, interpreted as the loops of Henle.
Zinc $(\mathrm{Zn})$ exists as a divalent cation $(\mathrm{Zn} 2+)$. The kidney epithelium is the site of urinary zinc excretion and reabsorption. Zinc reabsorption occurs in all the downstream segments of the nephron; proximal tubule, Loop of Henle, and terminal nephron segments ${ }^{14}$. Most of the filtered $\mathrm{Zn}$ is reabsorbed along kidney proximal tubule ${ }^{15}$. The kidney is considered the primary eliminator of exogenous drugs and toxins; impairment of excretion predisposes it to various forms of injury. Development of new biomarkers is needed for the specific diagnosis of nephrotoxicity at earlier stage ${ }^{16}$. These biomarkers include brush bodrder enzyme such as Leucineaminopeptidase (LAP) ${ }^{17}$, Lysosomal enzyme such as $\mathrm{N}$-acetyl- $\beta$-D-glucosaminidase (NAG) $)^{18}$, and cytosolic enzyme such as $\alpha$-glutathion S-transferase $(\alpha-G S T)^{18}$. Thus, detection of enzymes in the urine potentially provides valuable information not only related to the site of tubular injury (proximal \& distal tubule) but also to the severity of injury ${ }^{16}$.

Renal tubular cells, in particular proximal tubule cells, are vulnerable to the toxic effects of drugs because their role in concentrating and reabsorbing glomerular filtrate exposes them to high levels of circulating toxins ${ }^{19}$. Although most nephrotoxicity occurs in the proximal part of the nephron, some chemicals damage distal tubules. The function of these structures facilitates their vulnerability to toxicants ${ }^{20}$.

Drug addiction has been associated with various forms of renal diseases which may be related to direct effect of the drugs themselves while others are caused by complications related to drug abuse ${ }^{21}$.

The present work aims to investigate the effect of tramadol addiction on urinary excretion of some metals (e.g. copper, zinc and calcium) in relation to structural integrity of proximal tubules which were evaluated by measuring the urinary excretion of proximal tubular specific enzymes e.g. LAP and NAG. In addition, the study was extended to evaluate the effect of tramadol addiction coabused with cannabis.

\section{Materials \& methods}

The study was designed to be a comparative cross-sectional one from December 2015 to March 2016. Participants in the present investigation were recruited on voluntary bases from non-smoking males attending the outpatient clinic, El-Demerdash hospital, Ain-Shams University, for treatment of drug addiction. All partici- 
pates were subjected to interview using a questionnaire designed to obtain information about previous medical and occupational history, medication intake, actual health status, and subjective symptoms. All subjects underwent a routine clinical examination and a routine urinalysis. The interview and clinical examination were performed by the clinic physicians under the supervision of one of the authors. Participants of the control group were recruited from relatives of the addicted participants after applying the same exclusion criteria and clinical examination. A participant was excluded from the present study if he had:

1. A history of disease affecting the kidney before onset of addiction or any disease likely to impair renal function or affect the urinary excretion of the investigated parameters e.g. (diabetes mellitus, hypertension, collagen diseases as systemic lupus erythromatosis, Urinary tract disease, Rheumatoid arthritis and gout.

2. A previous or present exposure to agents capable of damaging the kidney, heavy metals such as lead $(\mathrm{Pb} 2+)$ and cadmium $(\mathrm{Cd} 2+)$ as well as other nephrotoxins such as organic solvents.

3. Regular and prolonged treatment by drugs affecting the kidney e.g. aminoglycosides and antirheumatic drugs. 4. Dental mercury amalgam filling as it may affect the kidney.

5. Cigarette smoker.

A total of sixty-five males were included in the present study and divided into three groups as follows: Control group (G1) was comprised of 19 males, Tramadol addicts (G2) were comprised of 18 males, Tramadol coabused with cannabis addicts (G3) was comprised of 28 males.

\section{Sampling}

Before starting treatment from addiction, morning urine sample was collected from each participant into $100 \mathrm{ml}$ sterilized plastic container and centrifuged at $4500 \mathrm{rpm}$ for 5 minutes, and then the clear supernatant was distributed in polyethylene vials ( $1.5 \mathrm{ml}$ capacity). One vial was used on the same day of urine collection for measuring tramadol (Tr) and cannabis in urine, the rest of vials were stored at $-20^{\circ} \mathrm{C}$ without preservatives until analyzed within 2 weeks.

\section{Methods}

Each urine sample was analyzed for the determination of: 1. Urinary tramadol (U.Tr) concentration by immunalysis using immunalysis EIA kit (immunalysis corporation, USA).

2. Urinary $\triangle 9$-THC concentration by DRI ${ }^{\circledR}$ cannabinoid assay (Microgenics, USA).

3. Urinary NAG and LAP concentration for the assessment of proximal tubular structural integrity by colorimetric method using NAG kit (Diazymelaboratotries, USA) and LAP kit (Randox, UK).

4. Urinary $\mathrm{Cu}, \mathrm{Zn}$, and $\mathrm{Ca}$ concentration for assessment of reabsorption integrity of the proximal tubules by Thermo Scientific ICE 3000 Series Atomic Absorption Spectrophotometer, England.

5. Urinary creatinine (U. Cr) concentration by Jaffe kinetic method using kit (Greiner Diagnostic GmbH, Germany).

\section{Statistical analysis}

Data was tabulated as mean $\pm \mathrm{SD}$. ANOVA was used to compare between more than two means of independent groups. In case of parametric data, if ANOVA was statistically significant, Post Hoc test was used to compare between each two means, while Mann- Whitney and Kruskall-Wallis tests were used for non-parametric data. Correlation coefficient was calculated to examine the relation between investigated urinary parameters. Results were considered statistically significant at $\mathrm{P}<0.05$.

\section{Results and discussion}

Regarding age, results of the present study (Table 1) showed that the three investigated groups were of comparable age since there was insignificant difference between G1 and each of G2 (P1 > 0.05) and G3(P2 > 0.05) as well as between $\mathrm{G} 2$ and $\mathrm{G} 3(\mathrm{P} 3>0.05)$, suggesting that age has no effect on the investigated urinary parameters. Concerning the investigated urinary enzymes of structural integrity of the proximal tubules (U.NAG/U.Cr and U.LAP/ U.Cr), data in (Table 1) demonstrated insignificant difference between the three investigated groups, suggesting that tramadol did not cause a damaging effect on the structural integrity of the proximal tubules, and even coabuse of cannabis with tramadol addiction has no effect on the structural integrity of the proximal tubules. This suggests that neither tramadol addiction alone nor 
tramadol coabused with cannabis affects the structural integrity of the proximal tubules among the investigated addicted individuals in the present study. These findings support the results reported by others ${ }^{22}$.

Regarding the effect of addiction on reabsorption integrity of the nephron for U.Cu/U.Cr and U.Zn/U.Cr as well as U.Ca/U.Cr, results in (Table 1) showed insignifi- cant changes $(\mathrm{P} 2>0.05)$ in urinary excretion of $\mathrm{U} . \mathrm{Cu} / \mathrm{U}$. $\mathrm{Cr}$ and U.Zn/U.Cr among the three investigated groups, suggesting also that neither tramadol addiction alone nor coabused with cannabis could affect the reabsorption integrity of the nephron for both $\mathrm{Cu}$ and $\mathrm{Zn}$.Also, this suggests that cannabis itself has no effect on the reabsorption integrity of the nephron for U.Cu/U.Cr and U.Zn/U.Cr.

\title{
Table 1: Data (Mean \pm SD) of investigated parameters among different studied groups:
}

\begin{tabular}{|c|c|c|c|c|}
\hline parameters & 9) $\mathrm{G}_{1}(\mathrm{n}=1$ & $\begin{array}{r}\mathrm{G}_{2}( \\
\mathrm{n}=18)\end{array}$ & $\begin{array}{r}\mathrm{G} 3( \\
\mathrm{n}=28)\end{array}$ & $\mathrm{P}$ \\
\hline Age (Years) & $23.79 \pm 3.91$ & $28.78 \pm 6.76$ & $26.82 \pm 5.45$ & $\mathrm{P}>0.05$ \\
\hline $\begin{array}{l}\text { Addiction Duration } \\
\text { (Years) }\end{array}$ & ---- & $3.97 \pm 3.97$ & $7.79 \pm 4.70$ & $\mathrm{P}>0.05$ \\
\hline U.Tr/U.Cr $\quad(\mathrm{mg} / \mathrm{gm})$ & ---- & $2629.92 \pm 5381.81$ & $1394.61 \pm 2951.20$ & $\mathrm{P}>0.05$ \\
\hline U.THC/U.Cr (mg/gm) & ---- & ---- & $0.18 \pm 0.22$ & $\mathrm{P}>0.05$ \\
\hline
\end{tabular}

\begin{abstract}
$\mathrm{N}$ : Number of individuals participated in each investigated group.
On comparing the three investigated groups using ANOVA, (Table 1) revealed a significant increase $(\mathrm{P}<0.05)$ in the urinary excretion of calcium and insignificant differences regarding all others investigated parameters.
\end{abstract}

Concerning the effect of addiction on urinary excretion of U.Ca/U.Cr, results in (Table 2) revealed a significant increase in U.Ca/U.Cr excretion among tramadol addicted group (G2) (P1 < 0.05) whencompared with (G1), suggesting that tramadol addiction causes reabsorption impairment of the nephron function regarding urinary calcium. This finding and suggestion receive support from the report that opioids cause increased levels of growth hormone and vasopressin ${ }^{23}$. 
Table 2: Comparison between different investigated groups regarding urinary calcium excretion
Studied groups
U. $\mathrm{Ca} / \mathrm{U} . \mathrm{Cr}$
$\mu \mathrm{g} / \mathrm{mg} \mathrm{Cr}$
$\mathbf{G}_{1} \quad$ Control group $(\mathrm{N}=19)$
Mean \pm SD
$39.41 \pm 12.19$
$\mathbf{G}_{2} \quad$ Tramadol addicts group $(\mathrm{N}=18)$
Mean \pm SD P1
$70.50 \pm 46.97$
$<0.05$

$\mathbf{G}_{3} \quad$ Tramadol coabused with cannabis group $(\mathrm{N}=28)$

Mean \pm SD P2

$$
\begin{gathered}
84.48 \pm 73.54 \\
<0.05 \\
<0.05
\end{gathered}
$$

\begin{abstract}
$\mathrm{N}$ : Number of individuals participated in each investigated group,
P1: G2 compared with G1, P2: G3 compared with G1, P3: G3 compared with G2.

In addition, (Table 2) demonstrated a significant difference $(\mathrm{P}<0.05)$ in the urinary calcium excretion in each of the two addicted groups (G2and G3) on comparing each of them with the control group (G1), as well as on comparing both of them together.
\end{abstract}

It was reported that growth hormone excess such as occurs in acromegaly causes hypercalciuria which appears to be a tubular effect and that vasopressin may increase calciumexcretion due to its effect on reducing calcium transport the thick ascending limb ${ }^{24}$. Furthermore, (Table 2) showed a significant increase in U.Ca/U.Cr excretion among tramadol coabused with cannabis group (G3) (P2 $<0.05)$ when compared with (G1), and this excretion was also significantly increased more than the one in tramadol addicted group (G2) on comparison between (G3) and (G2), suggesting that cannabis may have a synergetic effect to the impairment effect of tramadol on reabsorption of calcium along the nephron. This suggestion is supported by results in (Table 2) which demonstrated a significant increase in U.Ca/U.Cr excretion intramadol coabused with cannabis group (G3) (P2<0.05) when compared with tramadol addicted group (G2), and the finding of a significant correlation $(\mathrm{r}=0.5, \mathrm{P} 2<0.01)$ between U.Ca/U.Cr and U.THC/U.Cr levels in (G3) (Table
4). Moreover, other investigators ${ }^{25}$ reported mild kidney function decline among patients who had used marijuana, and others reported that tramadol has negative impacts on kidney function in human ${ }^{26}$ and experimental animals ${ }^{27}$ as evidenced by an increase in BUN and serum creatinine levels. Other studies reached similar results ${ }^{28,29}$. Results of the present study (Table 1) showed that the two addicted groups were having different addiction duration, and since the addiction duration in G3 is longer than in G2, it could be suggested that the abuser had started addiction with only one drug and after a period of time (that is with increasing age) the abuser started the coabuse of the second drug. This suggestion is supported by the report of others ${ }^{30}$ who found that for the cases of tramadol abuse, $97 \%$ of the drug addicts used tramadol in combination with other drugs or they had a previous history of addiction to substance of abuse. In addition, results in (Table 4) revealed a significant correlation $(\mathrm{r}=$ $0.552, \mathrm{P}<0.01)$ between age and addiction duration in G3, thus adding more support to the above suggestion.

African Health Sciences Vol 18 Issue 3, September, 2018 


\section{Table 3: Correlation coefficient ( $r)$ between investigated parameters in the tramadol addicted group:}

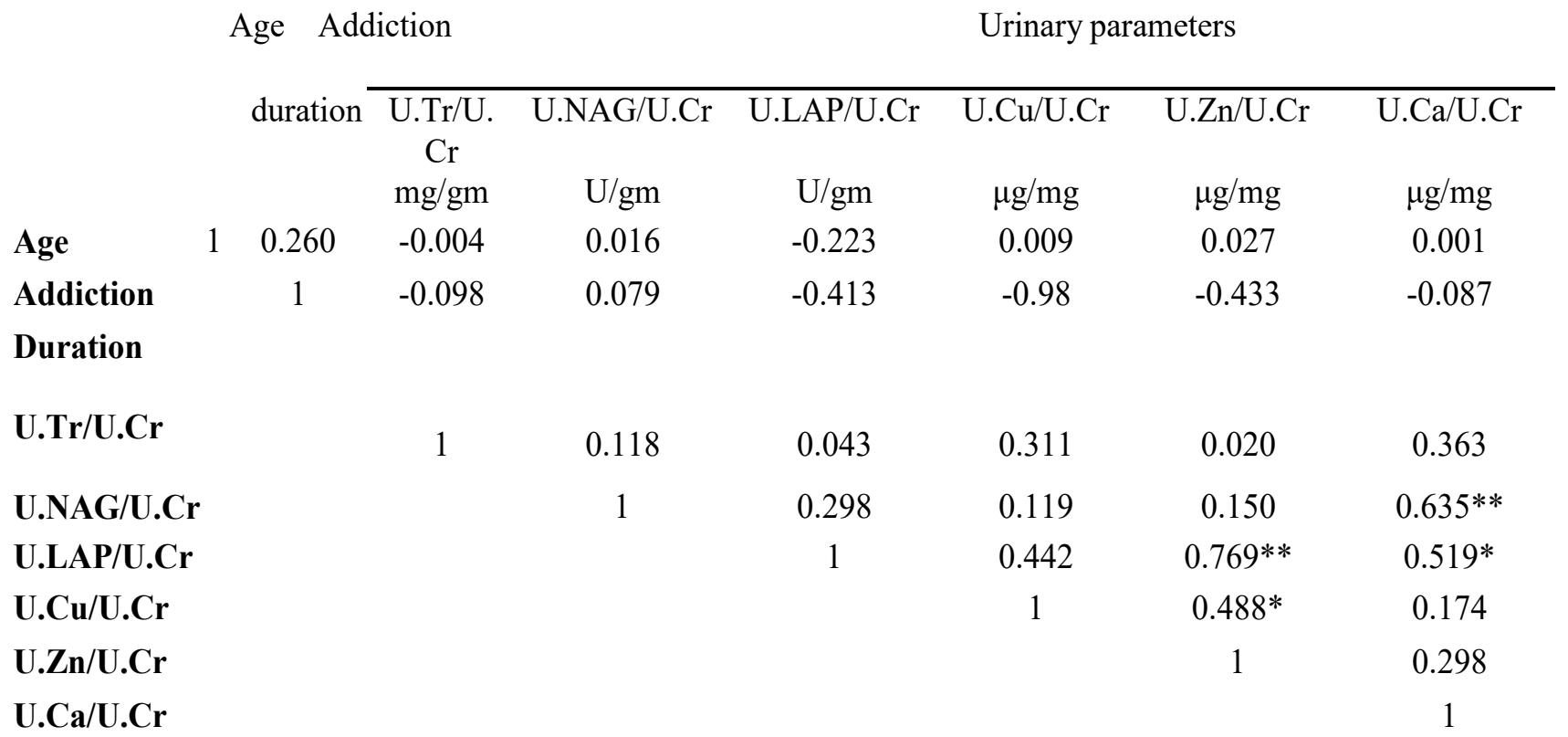

$*_{\mathrm{r}}$ is significant as $(\mathrm{P}<0.05) * * \mathrm{r}$ is highly significant as $(\mathrm{P}<0.01)$.

Results of the present work (Table 3) revealed a significant positive correlation between U.LAP/U.Cr and each of $\mathrm{U} . \mathrm{Zn} / \mathrm{U} . \mathrm{Cr}$ and U.Ca/U.Cr, and also between $\mathrm{U} . \mathrm{Cu} / \mathrm{U} . \mathrm{Cr}$ and $\mathrm{U} . \mathrm{Zn} / \mathrm{U} . \mathrm{Cr}$, as well as between U.NAG/U.Cr and U.Ca/U.Cr. 
Table 4: Correlation coefficient ( $r$ ) between investigated parameters in the tramadol coabused with cannabis addicted group:

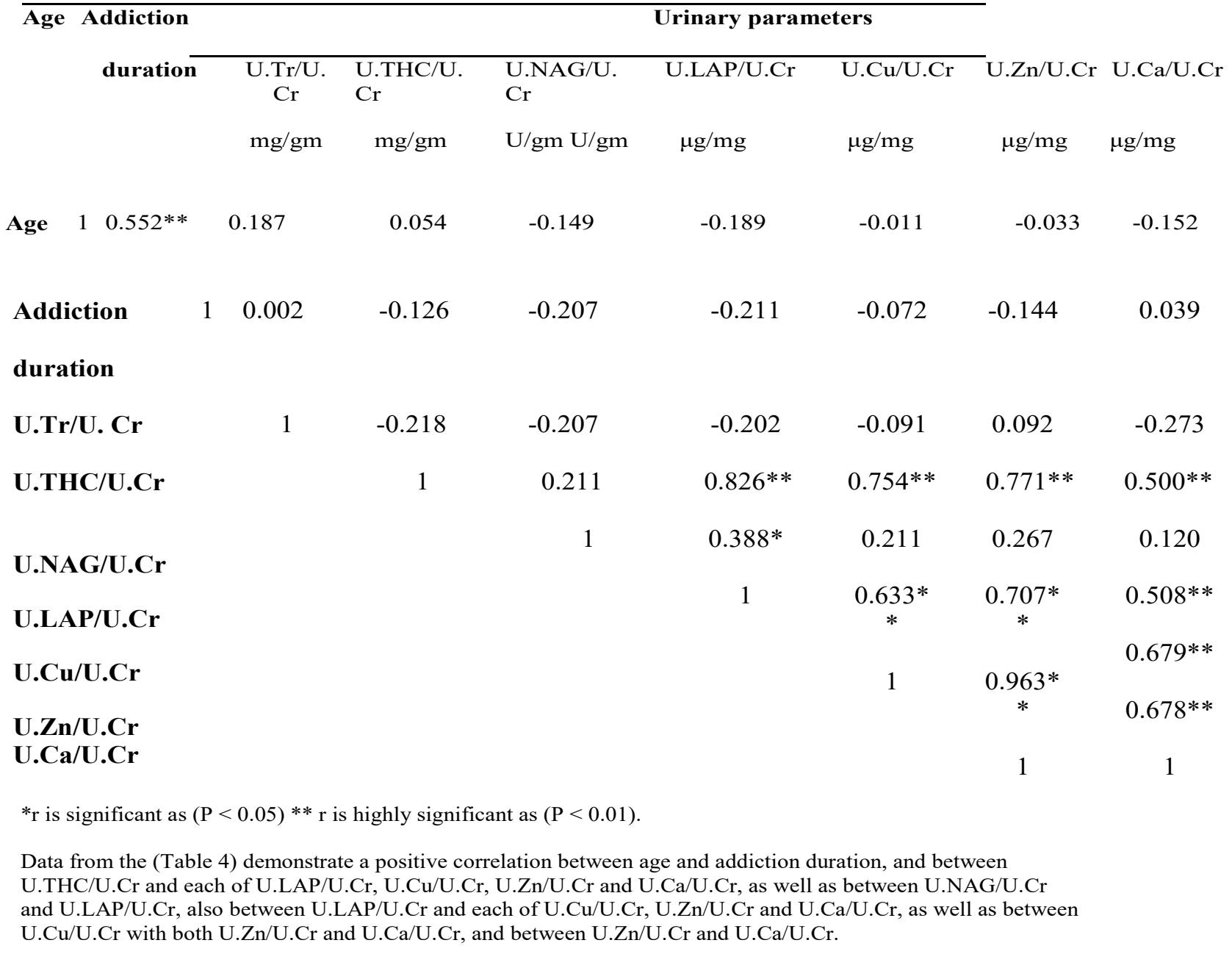

\section{Limitation of the study}

Absence of cannabis addicted group and the small number of recruited participants are the limitations in the present study.

\section{Conclusion}

Among the investigated addicted individuals, neither the addiction of tramadol alone nor in combination with cannabis was found to affect the structural integrity of proximal tubules. Moreover, reabsorption integrity of the nephron is affected only with respect to calcium reabsorption and not with respect to copper and zinc reabsorption. Also, to the best of our knowledge, this is the first study that investigated the effect of addiction of tramadol alone or coabused with cannabis on the reabsorption integrity of the nephron regarding urinary excretion of copper and zinc as well as calcium.

\section{Acknowledgment}

Authors acknowledge the financial support provided by Ain-Shams University, administration of environmental affairs. Also they acknowledge Dr. Haytham Hassan for drafting the questionnaire of the present study.

\section{Declaration of conflicting interests}

No Conflict of interest. 


\section{References}

1. Okasha A. Focus on psychiatry in Egypt. B J Psych. 2004; 185 (3): 266-272.

2. BamigbadeTA. Langford RML. Tramadol hydrochloride: an overview of current use. Hosp Med. 1998; 59: 373376.

3. Houmes RJM, Voets MA, Verkaaik A, Erdmann W, Lachmann B. Efficacy and safety of tramadol versus morphine for moderate and severe postoperative pain with special regard to respiratory depression. Anesth Analg. 1992; 74: 510-514.

4. Richter W, Barth H, Flohe L, Giertz H. Clinical investigation on the development of dependence during oral therapy with tramadol. Arrneimittelforschung. 1985; 35: $1742-1744$.

5. Cicero TJ, Inciardi JA, Adams EH, Geler A, Senay EC, Woody GE, et al. Rates of abuse of tramadol remain unchanged with the introduction of new branded and generic products: results of an abuse monitoring system 1994-2004. Pharmacoepidemiol Drug Saf. 2005; 14:851-859.

6. Hazekamp A, Grotenhermen F. Review on clinical studies with cannabis and cannabinoids 2005-2009. Cannabinoids. 2010; 5: 1-21.

7. Huestis MA. Human cannabinoid pharmacokinetics. Chem Biodivers. 2007; 4 (8): 1770 PubMed - 1804.

8. Reddi AS. Fluid, Electrolyte and Acid-Base Disorders: Clinical Evaluation and Management. New York: Springer; 2014.

9. Blaine J, Chonchol M, Levi M. Renal control of calcium, phosphate, and magnesium homeostasis. Clin J Am Soc Nephrol. 2014; 1-16.

10. Ellingsen DG, MØller LB, Aaseth J. Copper. In: Nordberg GF, Fowler BA, Nordberg M, editors. Handbook on the toxicology of metals. $4^{\text {th }}$ ed. Elsevier, 2015. pp. 765-786.

11. Moore SDP, Cox DW. Expression in mouse kidney of membrane copper transporters Atp7a and Atp7b. Nephron. 2002; 92: 629-634.

12. Linz R, Barnes NL, Zimnicka AM, Kaplan JH, Eppier B, Lutsenko S. Intracellular targeting of copper-transporting ATPase ATP7A in a normal and ATP7B kidney. Am J Physiol Renal Physiol. 2008; 294: F53-F61.

13. Wareing M, Ferguson CJ, Green R, Riccardi D, Smith CP. In vivo characterization of renal iron transport in the anaesthetized rat. J Physiol. 2000; 524: 581-586.
14. Barbier O, Jacquillet G, Tauc M, Poujeol P, Cougnon M. Acute study of interaction among cadmium, calcium, and zinc transport along the rat nephron in vivo. $A m \mathrm{~J}$ Physiol Renal Physiol. 2004; 287: F1067-F1075.

15. Ranaldi G, Perozzi G, Truong-Tran AL, Zalewski P, Murgia C. Intracellular distribution of labile $\mathrm{Zn}$ (II) and zinc transporter expression in kidney and MDCK cells. Am J Physiol Renal Physiol. 2002; 283: F1365-F1375.

16. Ferguson MA, Vaidya VS, Bonventre JV. Biomarkers of nephrotoxic acute kidney injury. Toxicol. 2008; 245: 182-193 PubMed .

17. Ren Q, Zhang Y, Yang J, Wei L, Zhao L, Yang Q. Detection of renal brush border membrane enzymes for evaluation of renal injury in neonatal scleredema. Pak J Med Sci. 2015; 31(1): 65-69.

18. Waikar SS, Bonventre JV. Biomarkers for the diagnosis of acute kidney injury. Nephron Clin Pract. 2008; 109: 192-197.

19. Perazella MA. Drug-induced nephropathy: an update. Expert Opin Drug Saf. 2005; 4 (4): 689-706.

20. Covington MD, Schnellmann RG. Pharmacological aspects of nephrotoxicity. In: DeBroe ME, Porter GA, editors. Clinical Nephrotoxins: Renal injury from drugs and chemicals. 3rd ed. Springer, 2008. pp. 73-83.

21. Kunis CL, Aggarwal N, Appel GB. Illicit drug abuse and renal disease. In: De Broe ME, Porter GA, editors. Clinical Nephrotoxins: Renal injury from Drugs and Chemicals. 3rd ed. Springer, 2008. pp. 591-612.

22. El-Safty IAM, Mohy El-Deen IE, El-Rasheed AH, El-Ashmawy MFM. Renal effects of tramadol addiction and cannabinoid abuse. RJPBCS 2015; 6 (1): 1212-1218. 23. Seyfried O, Hester J. Opioids and endocrine dysfunction. Br J Pain. 2012; 6 (1): 17-24.

24. Dirks JH. Factors Influencing Renal Calcium Excretion. In: Bichler KH, Strohmaier WL, editors. Nephrocalcinosis, Calcium Antagonists and Kidney. Springer-Verlag Berlin Heidelberg; 1988. pp. 43-51.

25. Vupputuri S, Batuman V, Muntner P, Bazzano LA, Lefante JJ, WheltonPK, et al. The risk for mild kidney function decline associated with illicit drug use among hypertensive men. Am J Kidney Dis. 2004; 43: 629-635.

26. Elmanama AA, Abu Tayyem NES, Essawaf HN, Hmaid IM. Tramadol-Induced Liver and Kidney Toxicity among Abusers in Gaza Strp, Palestine. JJBS. 2015; 8 (2): 133-137. 
27. Atici S, Cinel I, Cinel L, Doruk N, Eskandari G, Oral V. Liver and kidney toxicity in chronic use of opioids: An experimental long term treatment model. J Biosci. 2005; 2: 245- 252 PubMed .

28. Elyazji NR, Abdel-Aziz I, Aldalou A, Shahwan O. The effects of tramadol hydrochloride administration on the hematological and biochemical profiles of domestic male rabbits. IUG J Natural and Eng studies. 2013; 21: 51-65.
29. Rukhshanda S, Razia I, Muhammad NA, Anum Z, Javed I, Muhammad SA. Effects of tramadol on histopathological and biochemical parameters in mice (Musmusculus) model. Global J Pharmacol. 2014; 1: 14-19. 30. Cicero Tj, Adams EH, Geller A, Inciardi JA, Muńoz A, Schnoll SH, et al. A postmarketing surveillance program to monitor Ultram (tramadol hydrochloride) abuse in the United States. Drug Alcohol Depend. 1999; 57 (1):722. 